\title{
Caecal and faecal short-chain fatty acids and stool output in rats fed on diets containing non-starch polysaccharides
}

\author{
BY C. A. EDWARDS* AND M. A. EASTWOOD \\ Gastrointestinal Laboratory, Edinburgh University, Western General Hospital, Edinburgh EH4 2XU
}

(Received 23 March 1994 - Revised I8 July 1994 - Accepted 17 August 1994)

\begin{abstract}
The exact mechanisms by which non-starch polysaccharides increase stool output are unknown. In the present study the hypothesis that the site of fermentation and short-chain fatty acid (SCFA) accumulation is related to the action of non-starch polysaccharides (NSP) on stool output was tested. The basal diet ( $45 \mathrm{~g} \mathrm{NSP} / \mathrm{kg}$ ) of forty-three male Wistar rats was supplemented with $50 \mathrm{~g} / \mathrm{kg}$ of either guar, karaya, tragacanth, gellan, xanthan or ispaghula for $28 \mathrm{~d}$. A further twenty-three rats were maintained on the basal diet for the same time period. Faeces were then collected over $2 \mathrm{~d}$ and caecal contents obtained post-mortem. Caecal and faecal wet and dry weights and SCFA were measured. Each supplement had a different effect on the caecal and faecal contents but they appeared to fall into three groups when compared with the basal diet. In group 1, guar gum affected only caecal SCFA. It had no effect on stool output or faecal SCFA. In group 2, karaya increased caecal SCFA and tragacanth, karaya and xanthan increased faecal SCFA and faecal water. In group 3, ispaghula and gellan had no consistent effect on caecal or faecal SCFA concentrations but increased total faecal SCFA output and increased faecal wet and dry weight. Although the knowledge that SCFA are rapidly absorbed in the large intestine has led us to believe that they play no role in determining faecal output, these results suggest that in some cases where NSP are slowly fermented, and increase faecal SCFA, the role of the SCFA may need to be reassessed.
\end{abstract}

Non-starch polysaccharides: Short-chain fatty acids: Caecal fermentation: Stool output

The mechanisms by which non-starch polysaccharides (NSP) increase faecal output, and in particular faecal water, are not fully understood. NSP which are resistant to fermentation by bacteria in the large intestine are the most effective faecal bulkers, probably because they retain their water-holding capacity (WHC). The extent to which a NSP is fermented in the large intestine of an animal is dependent not only on the ease of fermentation but also on the time it remains within the large intestine (Van Soest et al. 1982). The factors which determine colonic transit time are not clear but propulsion may be increased by distension (Chauve et al. 1976), bile acids (Kirwan et al. 1975) or by the stimulation of the mucosa with the edges of particulate matter (Tomlin \& Read, 1988). The effect of fermentation products on motility has not been investigated thoroughly and short-chain fatty acids (SCFA) have been shown to inhibit motility in the caecum of the sheep (Svendsen, 1972) and the isolated rat colon (Squires et al. 1992), but to stimulate contractions in rat mid- and distal colonic strips (Yajima, 1985). The osmotic activity of the SCFA has been largely discounted as it has been shown that they are rapidly absorbed (McNeil et al. 1978). The major sites of fermentation are thought to be the caecum and proximal colon but it may be possible, if propulsion is stimulated before fermentation is complete, for fermentation of a NSP to continue further along the large intestine. If this occurs, the SCFA produced at distal sites may have a greater effect on stool output as the water remaining in the gut

* Present address: Department of Human Nutrition, University of Glasgow, Yorkhills Hospitals, Glasgow G3 8SJ, 
Table 1. In vitro fermentability and residual water-holding capacity (WHC) of non-starch polysaccharides (NSP) used in the present study*

\begin{tabular}{llc}
\hline \hline NSP & $\begin{array}{c}\text { Residual } \\
\text { WHC } \dagger \\
(\mathrm{g} / \mathrm{g})\end{array}$ & $\begin{array}{c}\text { Fermentability } \dagger \\
\text { (mmol SCFA } / 1 \\
\text { produced } \text { in vitro } \\
\text { after } 24 \mathrm{~h})\end{array}$ \\
\hline Guar & 1.87 & 71.4 \\
Tragacanth & $2 \cdot 13$ & 67.4 \\
Karaya & 4.65 & $24 \cdot 2$ \\
Xanthan & $2 \cdot 15$ & 63.4 \\
Ispaghula & ND & 40.0 \\
Gellan & 3.08 & 37.2 \\
Control & 0.91 & $15 \cdot 5$ \\
\hline \hline
\end{tabular}

ND, not determined; SCFA, short-chain fatty acids.

* Values from Adiotomre et al. (1990) and Edwards \& Eastwood (1992).

$\dagger$ After $24 \mathrm{~h}$ incubation with human faeces.

is related to the balance between SCFA production and absorption. In addition, as SCFA have been shown to influence the metabolism and turnover of colonic enterocytes, higher concentrations of SCFA at more distal sites, where disease is more common, may have an important role in pathology and treatment.

The aim of the present study was to test the hypothesis that the site of SCFA accumulation is related to the action of NSP on stool output. Further, that the fermentability of NSP is related to the site of SCFA accumulation and so influences faecal output. We therefore compared the caecal and faecal SCFA of rats fed on a variety of NSP with a range of in vitro fermentabilities (Adiotomre et al. 1990; Edwards \& Eastwood, 1992; Table 1) and have related these to the effects of the NSP on faecal output and faecal water.

\section{MATERIALS AND METHODS}

Animals

A total of sixty-six male Wistar rats, initial weight approximately $150 \mathrm{~g}$, were fed on a basal diet containing ( $\mathrm{g} / \mathrm{kg}$ ) : NSP (measured by the Englyst method, Englyst \& Cummings, 1984) 45 , digestible fat $29 \cdot 9$, digestible protein 129 , starch $629 \cdot 5$, sugar $22 \cdot 8$ (Special Diet Services Ltd., Witham, Essex) for 4 weeks before administration of the test diet. They were housed together in groups of up to five and maintained within the facilities of the Animal Unit, Western General Hospital, Edinburgh. The room was regulated to a $12 \mathrm{~h}$ light $-12 \mathrm{~h}$ dark schedule.

\section{Diets}

Rats were maintained on the basal diet for 4 weeks. Six groups of seven or eight rats were studied for the test NSP. As many rats were being studied and the number of metabolism cages was limited, the groups were staggered, with two groups being studied at any one time, and a control group at the beginning and end of the study giving a total of twentythree control animals. After 4 weeks each group was maintained on the basal diet supplemented with $50 \mathrm{~g} / \mathrm{kg}$ of either guar gum (molecular weight $\left(M_{\mathrm{r}}\right) 0.25 \times 10^{6}$, Sigma Chemical Co. Ltd., Dorset), xanthan (Keltrol T; $M_{\mathrm{r}} 2 \times 10^{6}$, Kelco Inc., San Diego, CA, USA), karaya $\left(M_{\mathrm{r}} 4.7 \times 10^{6}\right.$, Norgine Ltd., London), tragacanth $\left(M_{\mathrm{r}} 0 \cdot 5-1 \times 10^{6}, \mathrm{D} . \mathrm{M}\right.$. W. Anderson, Department of Chemistry, University of Edinburgh), gellan $\left(M_{\mathrm{r}} 0.5-1 \times 10^{6}\right.$, Kelco Inc.) or ispaghula (Richardson and Vicks Ltd, Egham, Surrey) for a further 4 weeks. 
Animals were allowed to feed and drink ad lib. Weight gain was monitored weekly. For $3 \mathrm{~d}$ at the end of the test diet period the animals were housed separately in metabolism cages.

\section{Sample collection and analysis}

While the animals were housed in the metabolism cages, food intake was measured. Faeces were collected daily. In a previous study (Edwards et al. 1992) we have shown that for faecal pellets over $1.5 \mathrm{~g}$ there is only $8 \%$ water loss over $24 \mathrm{~h}$ in our faecal collection system independent of diet. Values for wet weight are calculated allowing for this water loss.

After $3 \mathrm{~d}$ the animals were killed by cervical dislocation. The caecum and complete large intestine were removed. The two were separated and the contents carefully removed. The weight of the caecal contents was measured and the contents treated in an identical manner to the faecal material. The caecal and large intestinal tissue were carefully dissected free from fat and mesentery and washed with saline $(9 \mathrm{~g} \mathrm{NaCl} / \mathrm{l})$. They were then blotted and weighed. After weighing, the $\mathrm{pH}$ of faeces and caecal contents were adjusted to $>\mathrm{pH} 9$ before freeze-drying.

SCFA were analysed by gas chromatography of diethyl-ether extracts (Spiller et al. 1980). Faecal samples from the last $2 \mathrm{~d}$ in the metabolism cages were pooled and used for all analyses. Collections from the first day were not analysed to allow for the adaptation of the animals to the cages. Animals were placed in the metabolism cages in the morning. The faeces were collected before removing the animals on the final day. Any faeces passed during handling on the final day after removal from the cages were regarded as colonic contents. Previous studies have indicated that $2 \mathrm{~d}$ collections of faeces give values for stool output that are not significantly different from values obtained over longer collection periods (28 d; Edwards et al. 1992).

\section{Statistical analysis}

Results from rats given NSP were compared with rats given the basal diet by one-way analysis of variance followed by Student's $t$ test using the pooled estimate of standard deviation.

\section{RESULTS}

\section{Food intake, body and tissue weights}

Rats fed on guar gum and gellan ingested significantly more food, calculated without the contribution of the added NSP, than animals fed on the basal diet (Table 2). There was no significant difference for the other diets (Table 2). There was no difference in the final weight of any group of rats when compared with the rats fed on the basal diet. Ispaghulafed rats, however, had a higher final weight than some of the other groups of rats. This was due to a higher gain in body weight in the run-in period on the basal diet. The reason for this is unclear. Each analysis of the results is a comparison of each test group with the rats maintained on the basal diet and so this does not affect the overall conclusions (Table 2). Ingestion of all the NSP was associated with an increase in caecal tissue weight although this was most marked with guar and karaya. Only guar, tragacanth and ispaghula significantly increased colonic tissue weight. Guar and ispaghula increased colonic length (Table 2).

\section{Caecal contents}

The wet and dry weights of the contents of the caecum were increased by guar, tragacanth, karaya, and ispaghula: xanthan and gellan both decreased caecal content dry weight. Xanthan also decreased caecal content wet weight (Table 3).

Guar gum increased the concentration of caecal SCFA as a component of both dry and 
Table 2. Mean food intake and caecal and colonic tissue variables of rats fed on a basal diet (45 $\mathrm{g}$ non-starch polysaccharides $(\mathrm{NSP}) / \mathrm{kg}$ ) supplemented with $50 \mathrm{~g} \mathrm{NSP} / \mathrm{kg}$ from various sources, for $28 d \dagger$

\begin{tabular}{|c|c|c|c|c|c|}
\hline Diet & $\begin{array}{l}\text { Food intake } \ddagger \\
\text { (g dry wt } / \mathrm{d})\end{array}$ & $\begin{array}{c}\text { Caecal tissue wt } \\
\text { (g) }\end{array}$ & $\begin{array}{c}\text { Colon tissue wt } \\
\text { (g) }\end{array}$ & $\begin{array}{l}\text { Colon length } \\
\quad(\mathrm{mm})\end{array}$ & $\begin{array}{c}\text { Final rat wt } \\
(\mathrm{g})\end{array}$ \\
\hline Basal (n 23) & $22 \cdot 8 \S$ & 0.77 & $1 \cdot 50$ & 190 & $390-0$ \\
\hline Guar $(n 7)$ & $24 \cdot 8^{*}$ & $1 \cdot 12^{* * *}$ & $1 \cdot 86^{*}$ & $223^{* * *}$ & 353.8 \\
\hline Tragacanth $(n 7)$ & $24 \cdot 2$ & $1 \cdot 02 * * *$ & $1.73^{*}$ & 206 & $349 \cdot 1$ \\
\hline Karaya $(n 7)$ & $22 \cdot 2$ & $1.08 * * *$ & 1.47 & 190 & $382 \cdot 6$ \\
\hline Xanthan $(n 7)$ & $23 \cdot 6$ & $1 \cdot 0^{* * *}$ & 1.46 & 204 & $387 \cdot 1$ \\
\hline Gellan $(n 7)$ & $26 \cdot 9 * * *$ & $0.97 * * *$ & $1 \cdot 48$ & 191 & $349 \cdot 7$ \\
\hline Ispaghula ( $n$ 8) & $22 \cdot 8$ & $0.97 * * *$ & $2 \cdot 27^{* * *}$ & $219^{* *}$ & $411 \cdot 8$ \\
\hline Pooled SD & $1 \cdot 9$ & $0 \cdot 11$ & 0.33 & 20 & 39.6 \\
\hline
\end{tabular}

Mean values were significantly different from those of the basal diet: ${ }^{*} P<0 \cdot 05, * * P<0 \cdot 01,{ }^{* * *} P<0 \cdot 001$ (Student's $t$ test after ANOVA).

$\dagger$ For details of diets and procedures, see Table 1 and pp. 774-775.

$\$$ Excluding supplemented NSP.

$\S n 18$.

Table 3. Short-chain fatty acid (SCFA) content in the caecum of rats fed on a basal diet (45 $\mathrm{g}$ non-starch polysaccharides $(N S P) / \mathrm{kg}$ ) supplemented with $50 \mathrm{~g}$ NSP/kg from various sources, for $28 d \dagger$

\begin{tabular}{|c|c|c|c|c|c|c|}
\hline \multirow[b]{2}{*}{ Diet } & \multicolumn{3}{|c|}{ Total SCFA } & \multirow{2}{*}{$\begin{array}{l}\text { Wet wt of } \\
\text { caecal } \\
\text { contents }\end{array}$} & \multirow{2}{*}{$\begin{array}{l}\text { Dry wt of } \\
\text { caecal } \\
\text { contents }\end{array}$} & \multirow[b]{2}{*}{$\begin{array}{c}\text { Caecal } \\
\mathrm{pH}\end{array}$} \\
\hline & $\begin{array}{c}\mu \mathrm{mol} / \mathrm{g} \\
\mathrm{dry} \mathrm{wt}\end{array}$ & $\begin{array}{l}\mu \mathrm{mol} / \mathrm{g} \\
\text { wet wt }\end{array}$ & $\begin{array}{c}\mu \mathrm{mol} / \mathrm{g} \\
\text { in caecum }\end{array}$ & & & \\
\hline Basal (n 23) & $461 \cdot 7$ & $87 \cdot 6$ & $350 \cdot 3$ & $4 \cdot 00$ & $0 \cdot 75$ & $6.56+$ \\
\hline Guar $(n 7)$ & $699 \cdot 3^{*}$ & $113 \cdot 7^{* *}$ & $871 \cdot 5^{* * *}$ & $7 \cdot 58^{* * *}$ & $1 \cdot 25^{* * *}$ & $6 \cdot 58$ \\
\hline Tragacanth $(n 7)$ & $451 \cdot 8$ & $78 \cdot 0$ & $439 \cdot 7$ & $5 \cdot 63^{* * *}$ & $0.97 * *$ & 6.57 \\
\hline Karaya $(n 7)$ & $467 \cdot 1$ & $89 \cdot 7$ & $611 \cdot 2^{* * *}$ & $6.91^{* * *}$ & $1 \cdot 31 * * *$ & $6 \cdot 71$ \\
\hline Xanthan $(n 7)$ & $448 \cdot 2$ & $67 \cdot 5^{*}$ & $179 \cdot 0^{* *}$ & $2 \cdot 73^{* *}$ & $0-40^{* * *}$ & 6.6 \\
\hline Gellan $(n 7)$ & $585 \cdot 3^{*}$ & $62 \cdot 5^{* *}$ & 267.8 & $4 \cdot 24$ & $0-45^{* * *}$ & $7 \cdot 08 * * *$ \\
\hline Ispaghula $(n 7)$ & $431 \cdot 8$ & $67 \cdot 3^{*}$ & $464 \cdot 9^{*}$ & $6.91^{* * *}$ & $1 \cdot 1 * * *$ & $6 \cdot 38$ \\
\hline Pooled SD & $96 \cdot 8$ & $18 \cdot 3$ & $136 \cdot 4$ & 0.90 & $0 \cdot 18$ & 0.27 \\
\hline
\end{tabular}

Mean values were significantly different from those for the basal diet: ${ }^{*} P<0.05,{ }^{* *} P<0.01,{ }^{* * *} P<0.001$ (Student's $t$ test after ANOVA).

$\dagger$ For details of diets and procedures, see Table 1 and pp. 774-775.

$\ddagger n 18$.

wet weights (Table 3). Guar also increased the total amount of SCFA in the caecum. Gellan increased SCFA measured as a component of dry weight but reduced SCFA concentration per $g$ wet weight, and had no effect on total amount of SCFA in the caecum. Xanthan decreased the SCFA concentration per $g$ wet weight and the total amount of SCFA in the caecum. Ispaghula also decreased SCFA concentration per $\mathrm{g}$ wet weight probably reflecting the increased proportion of water in the caecum. Tragacanth had no significant effect on amount or concentration of SCFA.

Tragacanth significantly reduced, whereas gellan increased, the molar proportions of acetic acid in the caecum (see Table 5). Ispaghula increased the proportion of propionic acid and decreased the proportion of butyric acid whereas gellan had the opposite effect. 
Table 4. Mean faecal output and faecal short-chain fatty acid (SCFA) content of rats fed on a basal diet ( $45 \mathrm{~g}$ non-starch polysaccharides $(N S P) / \mathrm{kg}$ ) supplemented with $50 \mathrm{~g} \mathrm{NSP} / \mathrm{kg}$ from various sources, for $28 d \dagger$

\begin{tabular}{|c|c|c|c|c|c|c|c|c|}
\hline & \multicolumn{2}{|c|}{ Faecal output (g/d) } & \multirow{2}{*}{$\begin{array}{c}\text { Faecal } \\
\text { water } \\
\text { (g/kg) }\end{array}$} & \multirow{2}{*}{$\begin{array}{c}\text { Faecal } \\
\text { water } \\
\text { (g) }\end{array}$} & \multicolumn{3}{|c|}{ Total faecal SCFA } & \multirow[b]{2}{*}{$\begin{array}{c}\text { Faecal } \\
\text { pH }\end{array}$} \\
\hline & Wet wt & Dry wt & & & $\begin{array}{c}\mu \mathrm{mol} / \mathrm{g} \\
\text { dry wt }\end{array}$ & $\begin{array}{l}\mu \mathrm{mol} / \mathrm{g} \\
\text { wet wt? }\end{array}$ & $\mu \mathrm{mol} / \mathrm{d}$ & \\
\hline Basal (n 23) & $3 \cdot 26$ & $1 \cdot 58$ & 5348 & $1 \cdot 70$ & $86 \cdot 3$ & $40 \cdot 3$ & $124 \cdot 1$ & $7 \cdot 27 \|$ \\
\hline Guar $(n 7)$ & 3.85 & 1.61 & $569^{\circ}$ & $2 \cdot 23$ & $91 \cdot 6$ & $39 \cdot 5$ & 153.9 & 6.97 \\
\hline Tragacanth $(n 7)$ & $4 \cdot 65^{* *}$ & $2 \cdot 01^{*}$ & 564 & $2 \cdot 64^{* *}$ & $125 \cdot 5$ & $53 \cdot 9 *$ & $248 \cdot 2^{* *}$ & $6.89^{*}$ \\
\hline Karaya $(n 7)$ & $4 \cdot 92^{* * *}$ & 1.95 & $603^{* *}$ & $2 \cdot 97^{* * *}$ & $139 \cdot 5^{*}$ & $55 \cdot 1$ & $273 \cdot 0^{* *}$ & ND \\
\hline Xanthan ( $(7)$ & $4 \cdot 73^{* *}$ & 1.86 & 602 & $2 \cdot 87^{* * *}$ & $183 \cdot 5^{* * *}$ & $71 \cdot 3^{*}$ & $351 \cdot 8^{* * *}$ & $6.43 * * *$ \\
\hline Gellan $(n 7)$ & $6 \cdot 11 * * *$ & $2 \cdot 68 * * *$ & 563 & $3 \cdot 44^{* * *}$ & $72 \cdot 7$ & $31 \cdot 7$ & $191 \cdot 3$ & 7.04 \\
\hline Ispaghula $(n 8)$ & $5.87 * * *$ & $2 \cdot 56^{* * *}$ & 652 & $3 \cdot 68 * * *$ & $108 \cdot 7$ & $39 \cdot 9$ & $238 \cdot 1 * *$ & $6.69^{* * *}$ \\
\hline Pooled SD & $1 \cdot 10$ & 0.48 & 38 & 0.74 & $39-6$ & $13 \cdot 6$ & $87 \cdot 3$ & 0.36 \\
\hline
\end{tabular}

ND, not determined.

Mean values were significantly different from those for the basal diet: ${ }^{*} P<0.05,{ }^{* *} P<0.01,{ }^{* * *} P<0.001$ (Student's $t$ test after ANOVA).

$\dagger$ For details of diets and procedures, see Table 1 and pp. 774-775.

$\ddagger$ Assuming $8 \%$ water loss.

$\S n 22$.

$\| n 18$.

Table 5. Molar proportions of short-chain fatty acids (SCFA) in caecal contents and faeces of rats fed on a basal diet (45 $\mathrm{g}$ non-starch polysaccharides $(N S P) / \mathrm{kg}$ ) supplemented with $50 \mathrm{~g} \mathrm{NSP} / \mathrm{kg}$ from various sources for $28 \mathrm{~d} \dagger$

\begin{tabular}{|c|c|c|c|c|c|c|}
\hline & \multicolumn{3}{|c|}{ Caecal SCFA } & \multicolumn{3}{|c|}{ Faecal SCFA } \\
\hline & Acetic & Propionic & $\mathrm{N}$-butyric & Acetic & Propionic & N-butyric \\
\hline Basal (n 23) & $66 \cdot 2$ & $17 \cdot 3$ & $13 \cdot 0$ & $80 \cdot 0$ & 9.7 & $5 \cdot 0$ \\
\hline Guar $(n 7)$ & $64 \cdot 8$ & $16 \cdot 3$ & $15 \cdot 0$ & $85 \cdot 1^{*}$ & $9 \cdot 3$ & $0.95^{* * *}$ \\
\hline Tragacanth $(n 7)$ & $61 \cdot 5^{*}$ & $19 \cdot 7$ & $14 \cdot 0$ & $85 \cdot 0^{*}$ & $9 \cdot 6$ & $1 \cdot 7^{* *}$ \\
\hline Karaya $(n 7)$ & 67.9 & $15 \cdot 7$ & $12 \cdot 2$ & $76 \cdot 2$ & $13 \cdot 9 *$ & $3 \cdot 3$ \\
\hline Xanthan $(n 7)$ & $66 \cdot 1$ & $15 \cdot 6$ & 13.6 & $74 \cdot 1^{*}$ & $13 \cdot 3^{*}$ & $6 \cdot 1$ \\
\hline Gellan $(n 7)$ & $71 \cdot 3^{*}$ & $11 \cdot 5^{* * *}$ & $19 \cdot 0 * * *$ & $71 \cdot 3^{* * *}$ & $11 \cdot 5$ & 60 \\
\hline Ispaghula ( $n$ 8) & $66 \cdot 1$ & $22 \cdot 5^{* *}$ & $9 \cdot 4^{*}$ & $78 \cdot 6$ & $14 \cdot 1^{*}$ & 5.0 \\
\hline Pooled SD & 4.9 & 3.5 & $3 \cdot 6$ & $5 \cdot 3$ & $4 \cdot 0$ & $2 \cdot 3$ \\
\hline
\end{tabular}

Mean values were significantly different from those for the basal diet: ${ }^{*} P<0.05,{ }^{* *} P<0.01,{ }^{* * *} P<0.001$ (Student's $t$ test after ANOVA).

$\dagger$ For details of diets and procedures, see Table 1 and pp. 774-775.

There was no significant effect of any of the other NSP on the molar proportions of the SCFA.

Gellan increased caecal pH (Table 3); none of the other NSP had any effect.

\section{Faecal content}

Guar gum had no effect on faeces apart from causing a slight increase in water content. Tragacanth, karaya and xanthan increased faecal wet weight but not dry weight. They increased faecal SCFA concentration (although this did not achieve statistical significance for tragacanth), increased daily SCFA output and decreased faecal pH (Table 4). Gellan 
and ispaghula increased faecal wet and dry weight and ispaghula increased total SCFA output, but neither NSP had a significant effect on faecal SCFA concentrations.

Guar and tragacanth significantly increased the molar proportion of acetic acid in faeces (Table 5) whereas xanthan and gellan had the opposite effect. Karaya, xanthan and ispaghula all significantly increased the proportion of faecal propionic acid. Guar and tragacanth significantly decreased the proportion of butyric acid. None of the NSP tested significantly increased the molar proportion of butyric acid.

\section{DISCUSSION}

The NSP in the present study showed a range of effects on caecal and faecal SCFA and stool output that probably relate to their fermentability. The effects span a continuum which can be approximately divided into three groups. The first group, containing guar gum, was rapidly fermented, had the greatest effects on caecal SCFA and had little effect on faeces. Tragacanth, karaya and xanthan form the second group. These NSP had moderate effects on caecal SCFA, increased faecal SCFA concentration and increased faecal water. The final group, consisting of gellan and ispaghula, had little effect on the caecal SCFA. They had less effect on the total faecal SCFA than the second of group NSP and did not increase faecal SCFA concentration. However, they had the greatest effect on stool output increasing both wet and dry weights, probably in part due to some remaining physical structure.

The increase in stool water caused by the NSP in group 2 may be related to a slower fermentation at a more distal site, resulting in the increase in faecal SCFA concentration. This group had the highest faecal SCFA output. The role of the SCFA in this increase in faecal water is unclear. It was originally thought that SCFA in the colon caused increased stool water by osmotic activity (Forsythe et al. 1978). However, it has been shown that SCFA are rapidly absorbed from the colon (McNeil et al. 1978) and theoretically should not have a significant osmotic action. In the present study the increased concentrations of faecal SCFA indicate that this absorption capacity is not sufficient to maintain constant concentrations of SCFA and an increased osmotic pressure may still be achieved. The movement of the faecal stream may be related to the balance between production and absorption of SCFA.

When the increase in faecal SCFA concentration is plotted against the SCFA produced by each NSP in vitro (Table 1, Adiotomre et al. 1990; Edwards \& Eastwood, 1992) an n shaped curve is produced (Fig. 1). This supports the hypothesis that fermentability is related to the site of SCFA accumulation, rapidly fermented NSP producing no change in faecal SCFA, less rapidly fermented NSP increasing faecal SCFA, and NSP with low fermentability having little effect on faecal SCFA. Karaya does not fit into this $\mathbf{n}$ shaped plot due to the low fermentability in vitro compared with an apparent effect on faecal SCFA in the rat in vivo. Karaya was anomalous in the predictive index of SCFA stool output in the study of Adiotomre et al. (1990) with little effect on stool output in man despite a low fermentability and a high residual WHC. We have since carried out four further in vitro fermentations with karaya using different human faecal donors and found very little evidence of fermentation. The fermentability of karaya in the rat may be higher than that measured in human faeces. Moreover, the enzymes necessary for karaya fermentation may need to be induced by prior ingestion of karaya. Karaya data have thus been omitted from Fig. 1.

Vernia et al. (1988) showed that in patients with ulcerative colitis, increased faecal lactate was related to an increase in faecal water. However, this was associated with decreased faecal SCFA concentrations. Faecal SCFA and lactate did not play a role in Crohn's 


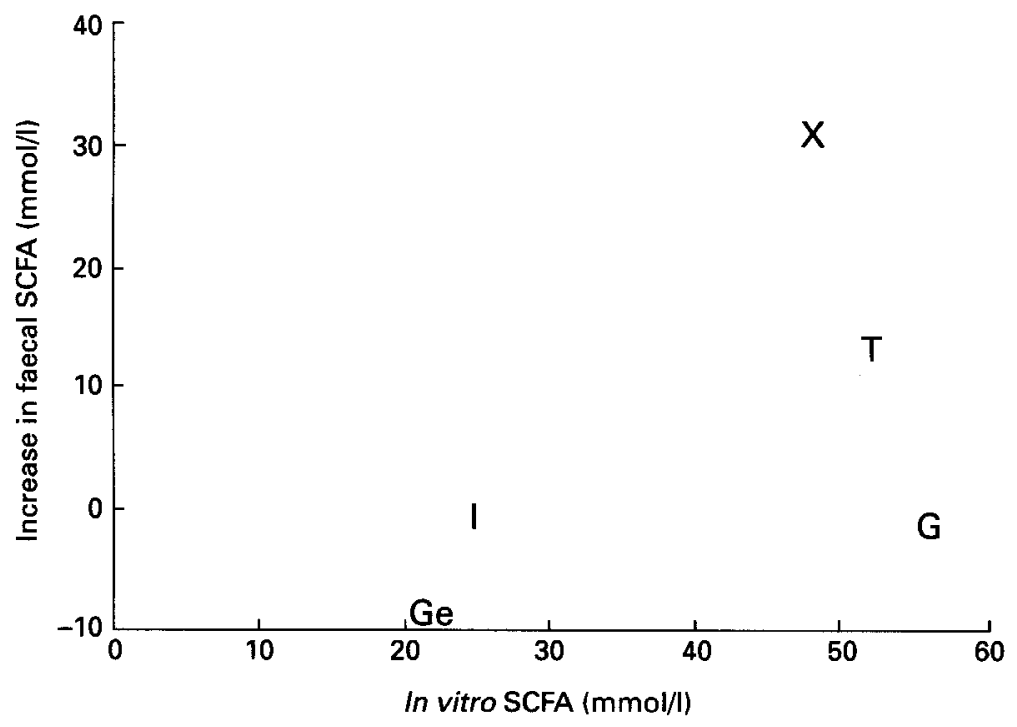

Fig. 1. The relationship between in vitro fermentation of non-starch polysaccharides (NSP) measured as total short-chain fatty acids (SCFA) produced, and the increase in faecal SCFA in the rat in vivo after 4 weeks ingestion of NSP. G, guar; Ge, gellan; I, ispaghula; X, xanthan; T, tragacanth.

disease. These patients, however, have inflammatory diarrhoea. They have abnormal absorption and motility, as well as probable abnormal carbohydrate fermentation, and their results are not representative of normal colonic physiology. The level of lactate in normal adult faeces is very low. In infants where it is high and in in vitro cultures of adult faeces, lactate production is associated with rapid fermentation of sugars or oligosaccharides. Lactate was not measured in the present study but is unlikely to play a role in the fermentation of slowly fermentable NSP. Other studies of ulcerative colitis have shown elevated faecal SCFA (Roediger et al. 1982).

There are several other possible mechanisms by which SCFA may affect stool output. SCFA may have significant actions on motility (Yajima, 1985). It is also possible that, due to slow fermentation, the WHC of these NSP is maintained for longer and further round the colon preventing water absorption until the NSP is fermented in a more distal part of the colon with a consequent increase in SCFA. We have previously shown that ispaghula did not increase faecal WHC (Edwards et al. 1992). The exact site of the loss of WHC of a NSP may be as important in its action on stool water as a significant increase in the WHC of faeces.

The contribution of bacterial cell mass to the faecal weight was not measured in the present study and it may be possible that there is a different role for the bacterial cells in the action of the different groups of NSP studied (Stephen \& Cummings, 1980).

None of the NSP decreased caecal pH despite obvious evidence of fermentation. This is in contrast to previous work in rats (Jacobs \& Lupton, 1986; Wyatt et al. 1988) and may relate to the lower dose used in the present study. The lower dose may explain why guar gum increased food intake in the present study in contrast to other reports (Wyatt et al. 1988). The physical form of the food may also be relevant. The diet in the present study was fed in the form of a paste. The physical form of food is not made clear in other studies. The reason that guar did not increase body weight despite an increased food intake is unclear but may indicate that $2 \mathrm{~d}$ measurement of food intake may not fully represent food 
intake over the entire 4-week period. There may also be increased energy costs associated with moving viscous NSP along the upper gastrointestinal tract.

Each NSP diet was associated with its own pattern of caecal and faecal SCFA. In the caecum, ispaghula was associated with a higher proportion of propionic acid whereas rats given gellan had more butyric acid. The reason for this difference in end-products is not clear. The predominance of acetic acid is generally higher in the faeces than in the caecum and reflects either a change in fermentation pattern in more distal colon or a difference in the utilization or absorption of the SCFA. However, those fibres which had the greatest effects on faecal water had the least predominance of acetic acid in faeces and in most cases a higher predominance of propionic acid, indicating the possibility of sustained fermentative activity in more distal parts of the colon.

In summary, the rate of fermentation of a dietary fibre and its subsequent effects on caecal and faecal SCFA appears to be an important factor in determining its effect on stool water and stool output. Fibres identified as group 2 in the present study appear to be fermented at a distal site in the colon producing the highest faecal SCFA concentrations and increased stool water. The mechanism for this action is not clear. It may be related to action of the SCFA on motility or a delay in the loss of WHC to a more distal site but the osmotic activity of SCFA produced in the distal colon should not be discounted.

We would like to thank the Proctor and Gamble Company for financial support.

\section{REFERENCES}

Adiotomre, J., Eastwood, M. A., Edwards, C. A. \& Brydon, W. G. (1990). Dietary fibre: in vitro methods that anticipate nutrition and metabolic activity in humans. American Journal of Clinical Nutrition 52, $128-134$.

Chauve, A., Devroede, G. \& Bastin, E. (1976). Intraluminal pressures during perfusion of the human colon in situ. Gastroenterology 70, 336-340.

Edwards, C. A., Bowen, J., Brydon, W. G. \& Eastwood, M. A. (1992). The effects of ispaghula on rat caecal fermentation and stool output. British Journal of Nutrition 68, 473-482.

Edwards, C. A. \& Eastwood, M. A. (1992). Comparison of the effect of ispaghula and wheat bran on rat caecal and colonic fermentation. Gut 33, 1229-1233.

Englyst, H. N. \& Cummings, J. H. (1984). A simplified method for the measurement of total non starch polysaccharides by gas liquid chromatography of constituent sugars as alditol acetates. Analyst 109, 937-942.

Forsythe, W. A., Chenoweth, W. L. \& Bennink, M. R. (1978). Laxation and serum cholesterol in rats fed plant fibers. Journal of Food Science 43, 1470-1476.

Jacobs, L. R. \& Lupton, J. R. (1986). Relationship between colonic luminal pH, cell proliferation and colon carcinogenesis in 1,2-dimethylyhydrazine treated rats fed high fiber diets. Cancer Research 46, $1727-1734$.

Kirwan, W. O., Smith, A. N., Mitchell, W. D., Falconer, J. D. \& Eastwood, M. A. (1975). Bile acids and colonic motility in the rabbit and human. Gut 16, 894-900.

McNeil, N. I., Cummings, J. H. \& James, W. P. T. (1978). Short chain fatty acid absorption by the human large intestine. Gut 19, 819-822.

Roediger, W. E. W., Heyworth, M., Willoughby, P., Piris, J., Moore, A. \& Truelove, S. C. (1982). Luminal ions and short chain fatty acids as markers of functional activity of the mucosa in ulcerative colitis. Journal of Clinical Pathology 35, 323-326.

Spiller, G. A., Chernoff, M. C., Hill, R. A., Gates, J. E., Nassar, J. J. \& Shipley, E. A. (1980). Effect of purified cellulose, pectin and a low residue diet on fecal volatile fatty acids, transit time and fecal weight in humans. American Journal of Clinical Nutrition 33, 734-739.

Squires, P. E., Rumsey, R. D. E., Edwards, C. A. \& Read, N. W. (1992). Effect of short chain fatty acids on contractile activity and fluid flow in rat colon in vitro. American Journal of Physiology 262, G813-G817.

Stephen, A. M. \& Cummings, J. H. (1980). The microbial contribution to human faecal mass. Journal of Medical Microbiology 3, 45-56.

Svendsen, P. (1972). Inhibition of cecal motility in sheep by volatile fatty acids. Nordic Veterinary Medicines 24 , 393-396.

Tomlin, J. \& Read, N. W. (1988). Laxative properties of plastic particles. British Medical Journal 297, $1175-1176$.

Van Soest, P. J., Jeraci, J., Fosse, T., Wrick, K. \& Ehle, F. (1982). Comparative fermentation of fibre in man and other animals. In Fibre in Humans and Animal Nutrition, pp. 75-80 [C. R. Wallace and L. Bells, editors]. Wellington: The Royal Society of New Zealand. 
Vernia, P., Gnaedinger, A., Hauck, W. \& Breuer, R. I. (1988). Organic anions and the diarrhoea of inflammatory bowel disease. Digestive Diseases and Sciences 33, 1353-1358.

Wyatt, G. M., Gee, J. \& Johnson, I. T. (1988). Intestinal microflora and gastrointestinal adaptation in the rat in response to non-digestible dietary polysaccharides. British Journal of Nutrition 60, 197-207.

Yajima, T. (1985). Contractile effect of short chain fatty acids on the isolated colon of the rat. Journal of Physiology 368, 667-678. 